\title{
Improving Demand for Health Services with the Involvement of Community Health Workers: A Case Study of Community Dynamics at Mosango Rural Health Zone in the Democratic Republic of Congo
}

\author{
John Etshumba Mukulukulu1, Dosithee Ngo-Bebe², Norbert Kimbamfu Mabanza ${ }^{3}$, \\ Fulbert Nappa Kwilu ${ }^{4}$
}

\footnotetext{
${ }^{1}$ Kinshasa School of Public Health, Management Department, University of Kinshasa, Kinshasa, Democratic Republic of Congo ${ }^{2}$ Kinshasa School of Public Health, Chief of Management Department, University of Kinshasa, Kinshasa, Democratic Republic of Congo

${ }^{3}$ Kinshasa Superior Technical and Medical Institute, University of Kinshasa, Kinshasa, Democratic Republic of Congo ${ }^{4}$ Kinshasa School of Public Health, Management Department, University of Kinshasa, Kinshasa, Democratic Republic of Congo Email: jeanmukulu@hotmail.com,ngobebed@gmail.com,mabanzakimbamfu@gmail.com,fnkwilu@gmail.com
}

\begin{abstract}
How to cite this paper: Mukulukulu, J.E., Ngo-Bebe, D., Mabanza, N.K. and Kwilu, F.N. (2020) Improving Demand for Health Services with the Involvement of Community Health Workers: A Case Study of Community Dynamics at Mosango Rural Health Zone in the Democratic Republic of Congo. Open Journal of Epidemiology, 10, 265-282.
\end{abstract}

https://doi.org/10.4236/ojepi.2020.103023

Received: May 12, 2020

Accepted: July 19, 2020

Published: July 22, 2020

Copyright $\odot 2020$ by author(s) and Scientific Research Publishing Inc. This work is licensed under the Creative Commons Attribution International License (CC BY 4.0).

http://creativecommons.org/licenses/by/4.0/

(c) (i) Open Access

\begin{abstract}
Introduction: DRC is one of Sub-Saharan Africa country with high infant and maternal mortality. The major problem is the underuse of health services because of inaccessibility on all fronts and also the population under-information to the health and development problems. Community participation is one of the basic requirements and basic principles of the Primary Health Care to solve this problem. That is why we choose Mosango RHZ to assess the improvement of demand for health services with the involvement of community health workers. Methods: We conduct a cross-sectional study carried out in Mosango RHZ in 2019. The study combined a mixed method (quantitative and qualitative) based on the realist evaluation approach which takes into account the Context-Mechanisms-Effects explained in the conceptual framework model. Results: Four predictive factors determine the improvement of health indicators with the involvement of CHWS in activities of the Mosango RHZ: Having attended school ( $\mathrm{p}=0.000$; $\mathrm{OR}=0.150)$; Having sufficient theoretical knowledge on malaria, diarrhoea, pneumonia, malnutrition, availability of inputs to treat these diseases $(p=0.004$; OR $=0.192)$; Having taken the training as CHWS and Having undergone more than one training as $\mathrm{CHW}(\mathrm{p}=0.013$; $\mathrm{OR}=0.074)$. This result corroborated with other studies carried in low- and middle-income countries like DRC. Conclusion:
\end{abstract}


The involvement of CHWs on improving demand for health services is effective in Mosango RHZ. The improvement of health service indicators and the effectiveness of this community intervention were conditioned by capacity building of the CHWs, the availability of inputs and the involvement of the community in the activities of the health zone through the Community Action Cells.

\section{Keywords}

CHWS Health Services Utilization, Mosango Rural Health Zone, Realist Evaluation, Democratic Republic of Congo

\section{Introduction}

Since 1982, DRC has implemented the Primary Health Care (PHC) strategy with the aim of making health care geographically, culturally and financially accessible to all people living inside. However, during the implementation of the national health policy in the DRC, it was important to underline that the major problem is the underuse of health services because of inaccessibility on all fronts and also the population under-information to the health and development problems which are bases of high morbidity and mortality in the population [1]. Surveys carried out by Planning Ministry with the support of WHO in 2001: Multi Indicators Cluster Survey (MICS2) and in 2018 (MICS4) have shown that children under five years mortality decreased between 2001 to 2010, going from $126 \%$ o to $97 \%$ ond from children under one year of age going from $213 \%$ o to $158 \%$ [2]. Despite these advances, it should be noted that child mortality remains high in the DRC. However, it is mainly due to diseases which are preventable by simple and unexpensive prevention or treatment measures [3]. The main causes of these deaths all ages combined are malaria, diarrhoea, pneumonia, measles, HIV/AIDS, tuberculosis in a field of malnutrition as well as complications linked to pregnancy and childbirth [4] [5]. The fight against these main death causes requires a high number of priority interventions including the integration of the minimum package of community activities at the operational level of health pyramid as adopted between the Health Ministry and its technical and financial partners. The implementation of this minimum package of community activities requires the involvement of community health workers who manage the health situation at the level of villages in rural areas or a square in an urban environment. The community health worker is a volunteer living in the village or the street chosen by citizens who takes care of 10 to 15 households in his place of residence [6]. A part of their time is devoted to community interest activities with a view to making a lasting contribution to the good development and health objectives of his village. The CHWs maintain continuous contact between the Health Centers and the households through family home visits. They organize and visit each household once or twice a month. CHW is there- 
fore the continuous link between the health center and the households in its health area [7]. The Global Strategy for Human Resources for Health by 2030 (resolution WHA69.19 (2016) presents series of policy options to maximize the benefits that Member States could derive from investing in human resources for health. Three or four Community health workers are part of the Community Animation Cell (CAC) which is a multisectoral structure for the development of the street and the village neighborhood. Each CAC sends its representative to elect the Health Area Development Committee (HADC). Community health workers receive information and benefit from trainings by the health center or Health zone management team (HZMT) on the management and prophylaxis of these diseases: malaria, diarrhoea, acute respiratory infections, malnutrition. CHWs also receive information on health, education and development and Communication for Social and Behavioral Change (CSBC) [8]. The minimum $\mathrm{CHW}$ activities package (MCAP) is mainly composed of the following 5 interventions: 1) Management of simple malaria, diarrhoea, acute respiratory infections, malnutrition; 2) Family planning through community distribution of contraceptive methods; 3) Participation in micro-planning of the EPI, Malaria Programme and Reproductive Health Programme; 4) Strengthening of routine vaccination through the recovery of children lost to follow-up and 5) Strengthening the Water, Hygiene and Environmental Sanitation program. All these interventions are monitored through participation in CAC and HADC meetings [6].

\section{Problematic}

Community participation is one of the basic requirements and basic principles of the Primary Health Care. Of course, Community health workers play a very important role in establishing a bridge between the health services (Health Centers) and the population receiving care. [9] [10]. The Astana Declaration in 2018 describes the desire to respond effectively to current and future challenges in the health field, by mobilizing all stakeholders, including health professionals, academic institutions, community health workers, civil society, local and international partners, organizations and funds, the private sector, religious organizations and others, around national policies, strategies and plans, in all sectors, with the objective to take joint measures for build stronger and more sustainable primary health care with a view to achieving universal health coverage [11] [12]. Despite the integration of Community health workers into health policy at the level of health zone in the DRC, a high percent of people (83\%) die at home without having used the health services set up, $75 \%$ of these deaths concern children between 0 and 5 years of age as well as pregnant and lactating women [13] [14]. Particularly at Mosango Health Zone the under-utilization of basic health services remains a major problem. To this, it should be added that the diseases for which the CHWs are responsible for prevention and community care remain cited among the main causes of death for all ages. A study carried out in Bangladesh in 2013 and another in Chile in 2017 shows that when community health workers are involved in the implementation of health activities in 
rural areas, the trend in health indicators changes positively [15] [16]. Thus, for this study we ask the question of whether the intervention of CHWS through the implementation of community minimum activities package (CMAP) contributed to the improvement of health service indicators in the HRZ of Mosango. From this questioning, we formulate the hypothesis according to which the introduction of CMAP under the responsibility of CHWS is a major intervention which contributes to the improvement of health service indicators. However, the effectiveness of this community intervention is conditioned by capacity building of the CHWs, the availability of inputs and the involvement of the community in the activities of the health zone through the Community Action Cells (CAC). Based on this hypothesis, our study has set itself general objective of analyzing the effectiveness of CHWS intervention on improving health indicators in the Mosango RHZ. And Specific objectives to: 1) Describe the knowledge, attitudes and practices of CHWS on the health activities at Mosango Rural Health zone; 2) Identify predictors of the improvement of health indicators in the Mosango RHZ linked to the involvement of CHWS and 3) Compare the evolution of health indicators at Mosango RHZ before and after CHWS involvement. Following these objectives, a conceptual framework model is proposed to explain CHWS contribution on the improvement of health indicators in Mosango RHZ as shown in Figure 1.

The conceptual framework model we develop in this study is adapted from Pawson and Tilley model that are among pioneers of the realist evaluation approach through the analysis of the intervention logic which includes elements of

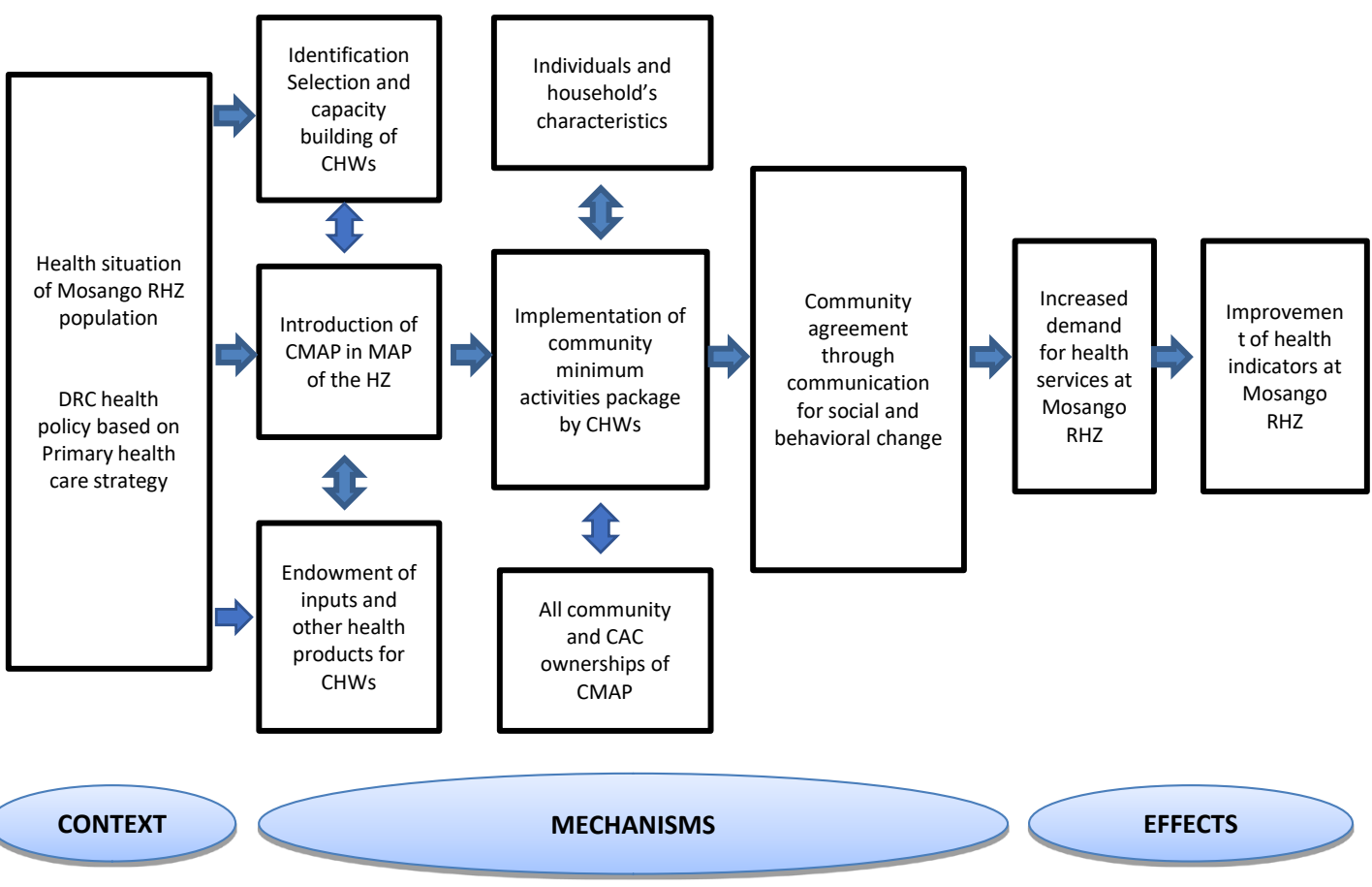

Figure 1. Conceptual framework model of the implementation of CMAP activities by CHWS to contribute to the improvement of health indicators at Mosango RHZ. Source: Authors adapted from PAWSON and Tilley model (1997). 
the context with input mechanisms to produce the expected effects or results in a health system. For Mosango RHZ, the Context is represented by the health, social and economic situation of its population, marked as in most of the Kwilu Province's HZ before the involvement of CHWS in the health system by a low rate of use of services: $25 \%$, Vaccine Coverage to EPI flagship antigens very low PENTA 3: 60\%, Measles Vaccine: 55\%. This is why the DRC health policy has integrated the CMAP managed by CHWS into the MAP of the HZs. It has the consequence before its implementation, the identification and choice of CHWS, capacity building and the provision of inputs to organize case management according to the 5 interventions of the CMAP CHWS [8]. Once all these conditions have been met, taking into account individuals and household's characteristics, the implementation of CMAP activities with the support of Technical and Financial Partners in the HZ, through awareness rising of the community by CHWS has led to behavior change in the community through communication for social and behavioral change. This led to their involvement in the activities of the health zone through the construction of health centers in durable materials in all 18 Health Areas, the sanitation of several villages and the use of health services in the health zone. It appears as effects, that we can observe the improvement of health indicators in the health zone, if at least the population actually used health services and that CHWS continue to be involved in the implementation CMAP activities in all health areas.

\section{Methodology}

\subsection{Studies Design and Population}

This is a cross-sectional study carried out in Mosango RHZ in 2019 with the use of activities report for 2015 to 2019. The study combined a mixed method (quantitative and qualitative) based on the realist evaluation approach which takes into account the "Context-Mechanisms-Effects" logic and the main mechanisms of which are organized around the integration of the CMAP activities of CHWS to extend at the community level the RHZ MAP. The population of this study consisted of all Community health workers, a total of 454 CHWs spread across the 18 health areas of the Mosango RHZ.

\subsection{Study Site Description}

Mosango Rural Health Zone is one of 20 Health Zones that counts Kwilu Province and $516 \mathrm{HZ}$ of DRC. It covers the sectors of MOSANGO, KINZENZENGO and a part of the Kwenge sector in MASI-MANIMBA Territory in the Democratic Republic of Congo. With an estimated population of 135.792 inhabitants in 2019, The HZ covers an area of $3350 \mathrm{Km}^{2}$ with a density of 40 inhabitants per $\mathrm{km}^{2}$ along the number 1 national road, between Kinshasa and Kikwit town. It is bounded to the north by the Yasa Bonga HZ, to the south by the Moanza HZ, to the east by the Vanga HZ and to the west by the Masimanimba HZ. It has 18 health areas with 10 CCS, 18 Health centers, 1 Reference Health Center and 1 
General Hospital. Population socio-economic situation is mainly dominated by the following main activities: agriculture, animal husbandry and subsistence fish farming. The purchasing power of the population is very low (around $1 \mathrm{u} \$ \mathrm{a}$ month) expressed by a high insolvency rate: $20 \%$ at the General Hospital [17].

\subsection{Sampling and Data Collection}

The study began with documentary review which consisted of collecting statistical data. It was a question of exploiting activities reports of the $\mathrm{HZ}$, which provides information on the CCS, HC, RHC, GH and HZCO, but also the specific report extracted from the DHIS2 software. It should however be stressed that this is official administrative data which, despite the questioning of their quality [17], can nevertheless identify trends which allow us to judge the evolution of indicators selected. These data are also those used by the HZ Management Team for the daily management of their activities. Starting from a population of 454 CHWs and using the EPI info software, the sample size was fixed at $208 \mathrm{CHWs}$, a figure increased by more than at least $10 \%$ to prevent refusals to respond and with a threshold $95 \%$ confidence and a $5 \%$ margin of error. The draw was made on the basis of the list of CHWs, with a sampling step of 2 units, from a number drawn at random between 1 and 10. In the end, our sample was made up of 234 $\mathrm{CHW}$, representing $52 \%$ of the base population. $\mathrm{CHWs}$ selected were visited in their respective villages or invited to Mosango city. All were interviewed by using a questionnaire. In total of the $234 \mathrm{CHWs}$ surveyed 227 were promotional CHWs compared to only $7 \mathrm{CHWs}$ providing care. Qualitative data were collected through three Focus groups discussion (FGD) who were organized for a total of 23 people identified by reasoned choice. The first consisted of 6 community leaders, the second of 6 Community health workers and the third of 11 executives of Mosango's health central zone office. An interview guide was used to conduct the discussions, which were recorded and subsequently encoded to retain most of sought information.

\subsection{Data Analysis}

Quantitative data collected was entered using the Epidata 3.1 software, and transferred after verification to SPSS (Statistical Package for the Social Sciences) version 23.0 (IBM, Chicago) for statistical analyzes. The data were summarized using frequency and proportions for categorical variables and means were compared using Student's t-test with standard deviations for quantitative variables. The association between categorical variables was tested using Pearson's or Likelihood-ratio. A Logistic prediction model was made using the backward procedure in order to identify factors associated with the dependent variable. Independent variables included sociodemographic and health services characteristics. Statistical significance was fixed at $\mathrm{p}=0.05$. Qualitative data from focus groups discussion: semi-structured interviews and the FGD were transcribed verbatim in Kikongo, one of main local languages, translated into French and checked by 
research team members. The opinions or information gathered from the participants by recording and taking notes. The transcripts were read and reread by the research team to ensure that it was compliant with the recording. Then after, we proceeded to codification using Atlas-ti 7 software. Next, content analysis uses a deductive thematic approach by an analysis matrix from the information pooling sheet.

\section{Results}

Our quantitative study results are summarized on 9 tables as shown in Tables 1-9.

Table 1. Socio-demographic characteristics of CHWs surveyed distribution.

\begin{tabular}{|c|c|c|c|}
\hline Variables & Average & $\begin{array}{l}95 \% \text { confidence interval } \\
\text { for the average }\end{array}$ & $\begin{array}{l}\text { Standard } \\
\text { deviation }\end{array}$ \\
\hline Age & 46.3 & {$[45.0 ; 47.6]$} & 9.9560 \\
\hline Marital status & $(\mathrm{n}=234)$ & $\%$ & \\
\hline Single & 9 & 3.8 & \\
\hline Monogamous marriage & 156 & 66.7 & \\
\hline Polygamic marriage & 39 & 16.7 & \\
\hline Divorced & 6 & 2.6 & \\
\hline Widower-Widow & 10 & 4.3 & \\
\hline Free union & 14 & 6.0 & \\
\hline \multicolumn{4}{|l|}{ School } \\
\hline No & 7 & 3 & \\
\hline Yes & 227 & 97 & \\
\hline \multicolumn{4}{|l|}{ Study level } \\
\hline Uneducated & 7 & 3.0 & \\
\hline Primary not completed & 12 & 5.1 & \\
\hline Primary completed & 10 & 4.3 & \\
\hline Secondary not completed & 109 & 46.6 & \\
\hline Secondary completed & 87 & 37.2 & \\
\hline Superior not completed & 8 & 3.4 & \\
\hline Superior completed & 1 & 0.4 & \\
\hline \multicolumn{4}{|l|}{ Religion } \\
\hline Catholic & 111 & 47.4 & \\
\hline Protestant & 56 & 23.9 & \\
\hline Revival church & 39 & 16.7 & \\
\hline Kimbanguists & 6 & 2.6 & \\
\hline Jehovah's witnesses & 4 & 1.7 & \\
\hline Muslim & 1 & 0.4 & \\
\hline Black church & 6 & 2.6 & \\
\hline Brahnamist & 1 & 0.4 & \\
\hline
\end{tabular}




\section{Continued}

\begin{tabular}{ccc}
\hline New apostolic & 8 & 3.4 \\
Other & 2 & 0.9 \\
CHWs type & & \\
Promotional CHW & 227 & 97.0 \\
Health care provider CHW & 7 & 3.0 \\
Have a job & 5 & 2.1 \\
No & 229 & 97.9 \\
Yes & 229 & \\
Profession outside CHW & 11 & 5 \\
State agent & 38 & 17 \\
Teacher & 130 & 57 \\
Farmer & 16 & 7 \\
Breeder & 20 & 9 \\
Trader & 14 & 6 \\
Others & & \\
& &
\end{tabular}

Table 2. Knowledge of the management of simple malaria, diarrhoea, acute respiratory infections and malnutrition of CHW surveyed distribution.

\begin{tabular}{ccc}
\hline Variables & $(\mathrm{n}=\mathbf{2 3 4})$ & $\%$ \\
\hline CHW's knowledge & & \\
Insufficient knowledge & 45 & 19.2 \\
Good knowledge & 189 & 80.8 \\
\hline
\end{tabular}

Table 3. Themes addressed during the capacity-building sessions received by CHW surveyed distribution.

\begin{tabular}{lcc}
\hline \multicolumn{1}{c}{ Training topics } & $\mathbf{n}=\mathbf{2 3 4}$ & $\%$ \\
\hline Population count & 127 & 54.3 \\
Malaria management and prevention & 69 & 29.5 \\
Diarrhoea & 29 & 12.4 \\
Pneumonia & 8 & 3.4 \\
Malnutrition & 44 & 18.8 \\
Exclusive breastfeeding & 21 & 9.0 \\
Children from 0 to 5 years old and pregnant women's vaccination & 32 & 13.7 \\
Infant and young Child feeding & 63 & 26.9 \\
Environmental sanitation and water promotion & 26 & 11.1 \\
Impregnated mosquito bednets distribution and promotion & 84 & 35.9 \\
Essential Family practices promotion & 20 & 8.5 \\
Health services used promotion (FP. IMCI. IMAM. PSC. PNC) & 53 & 22.6 \\
Assisted Child Birth promotion & 16 & 6.8 \\
Other subjects & 28 & 12.0 \\
\hline
\end{tabular}


Table 4. Knowledge of their attributions among the interventions of the CMAP of CHW's respondents distribution.

\begin{tabular}{ccc}
\hline Variables & $(\mathrm{n}=234)$ & $\%$ \\
\hline CHW's knowledge on promotional attributes & \\
Insufficient knowledge of promotional attributes & 78 & 33.3 \\
Good knowledge of promotional attributes & 156 & 66.7 \\
CHW's knowledge on the service attributions & \\
Insufficient knowledge of provider attributions & 185 & 79.1 \\
Good knowledge of provider attributions & 49 & 20.9 \\
\hline
\end{tabular}

Table 5. Practices description in relation to the CMAP of CHW surveyed.

\begin{tabular}{|c|c|c|}
\hline Variables & $(\mathrm{n}=234)$ & $(\%)$ \\
\hline \multicolumn{3}{|c|}{ Home visits } \\
\hline No & 1 & 0.4 \\
\hline Yes & 233 & 99.6 \\
\hline \multicolumn{3}{|c|}{ Counting book updating } \\
\hline No & 46 & 19.7 \\
\hline Yes & 188 & 80.3 \\
\hline \multicolumn{3}{|c|}{ Essential Family practices promotion } \\
\hline No & 36 & 15.4 \\
\hline Yes & 198 & 84.6 \\
\hline \multicolumn{3}{|c|}{ Vaccination and Birth registration promotion } \\
\hline No & 41 & 17.5 \\
\hline Yes & 193 & 82.5 \\
\hline \multicolumn{3}{|c|}{ Health services used promotion } \\
\hline No & 117 & 50.0 \\
\hline Yes & 117 & 50.0 \\
\hline \multicolumn{3}{|c|}{ Family kits distribution and promotion } \\
\hline No & 39 & 16.7 \\
\hline Yes & 195 & 83.3 \\
\hline
\end{tabular}

Table 6. Community Care Sites functionality description.

\begin{tabular}{ccc}
\hline Variable & $(\mathrm{n}=\mathbf{2 3 4})$ & $\%$ \\
\hline Community care sites functionality description & & \\
CCS bad functioning & 206 & 88.0 \\
CCS smooth functioning & 28 & 12.0 \\
\hline
\end{tabular}

Table 7. Predictors of the improvement of health indicators in Mosango RHZ linked to the involvement of CHWS.

\begin{tabular}{|c|c|c|c|c|}
\hline \multirow[t]{2}{*}{ Overall effectiveness of CHWS } & \multirow[t]{2}{*}{ OR } & \multicolumn{2}{|c|}{ CI OR ${ }_{95 \%}$} & $\mathbf{p}$ \\
\hline & & Lower bound & Upper bound & \\
\hline To have attended school & 0.150 & 0.055 & 0.409 & $0.000^{*}$ \\
\hline
\end{tabular}




\section{Continued}

Theoretical knowledge and management of simple malaria, diarrhoea, pneumonia and

0.055

0.409

$0.000^{*}$ malnutrition

Good knowledge

0.063

0.591

$0.004^{*}$

Have taken the training as CHWS

Yes

0.024

0.001

0.631

$0.025^{*}$

Training frequency

More than one training

0.074

0.010

0.573

$0.013^{*}$

Table 8. Health indicators evolution in the Mosango RHZ since CHW's intervention.

\begin{tabular}{|c|c|c|c|c|c|}
\hline \multirow{2}{*}{ No } & Observed Indicators & \multirow{2}{*}{$\begin{array}{c}\text { Baseline } \\
\text { value } 2010\end{array}$} & \multirow{2}{*}{$\begin{array}{l}\text { OBSERVED } \\
\text { VALUE } \\
2015\end{array}$} & \multirow{2}{*}{$\begin{array}{l}\text { OBSERVED } \\
\text { VALUE } \\
2018\end{array}$} & \multirow{2}{*}{$\begin{array}{l}\text { OBSERVED } \\
\text { VALUE } \\
2019\end{array}$} \\
\hline & Health services indicators & & & & \\
\hline 1 & Rate of curative services used & $25 \%$ & $40 \%$ & $55 \%$ & $60 \%$ \\
\hline 2 & Vaccination coverage in Penta 3 & $60 \%$ & $94 \%$ & $97 \%$ & $98 \%$ \\
\hline 3 & $\begin{array}{l}\text { Recovery of children lost to measle } \\
\text { vaccination }\end{array}$ & 24 & 176 & 543 & 609 \\
\hline 4 & Recovery of children lost to Penta 3 & 26 & 214 & 797 & 815 \\
\hline 5 & $\begin{array}{l}\text { Management of simple malaria on } \\
\text { children under } 5 \text { : treated cases }\end{array}$ & 11,492 & 22,089 & 26,278 & 26,764 \\
\hline 6 & $\begin{array}{l}\text { Management of pneumonia on children } \\
\text { under 5: treated cases }\end{array}$ & 584 & 1794 & 2576 & 2867 \\
\hline 7 & $\begin{array}{l}\text { Management of diarrhoea on children } \\
\text { under 5: treated cases }\end{array}$ & 663 & 1752 & 1452 & 1470 \\
\hline \multirow[t]{2}{*}{8} & $\begin{array}{l}\text { Management of tuberculosis: positive } \\
\text { detected cases }\end{array}$ & 54 & 95 & 96 & 98 \\
\hline & Community involvement indicators & & & & \\
\hline 1 & Holding of CAC meetings & $50 \%$ & $81 \%$ & $84 \%$ & $86 \%$ \\
\hline 2 & $\begin{array}{l}\text { Holding of Health care area committee } \\
\text { meetings }\end{array}$ & $50 \%$ & $88 \%$ & $84 \%$ & $89 \%$ \\
\hline 3 & Completion rate of CAC decisions & $30 \%$ & $63 \%$ & $58 \%$ & $64 \%$ \\
\hline 4 & $\begin{array}{l}\text { Completion rate of Health care area } \\
\text { committee decisions }\end{array}$ & $30 \%$ & $65 \%$ & $58 \%$ & $64 \%$ \\
\hline
\end{tabular}

Source: Mosango RHZ data drawn from specialized program and DHIS2 software.

Table 9. CHWs assessment on the effectiveness of their work.

\begin{tabular}{llcc}
\hline N0 & \multicolumn{1}{c}{ Observed indicators } & $\begin{array}{c}\text { Positive } \\
\text { assessment (\%) }\end{array}$ & $\begin{array}{c}\text { Insufficient } \\
\text { Appreciation (\%) }\end{array}$ \\
\hline 1 & Training received as Community health worker & 80.8 & 19.2 \\
2 & CHWS Knowledge on promotional activities & 66.7 & 33.3 \\
3 & CHWS Knowledge on care delivery activities & 20.9 & 79.1 \\
4 & Home visit & 99.6 & 0.4 \\
\hline
\end{tabular}




\begin{tabular}{|c|c|c|c|}
\hline \multicolumn{4}{|c|}{ Continued } \\
\hline 5 & Update of the count book & 80.3 & 19.7 \\
\hline 6 & Key family practices promotion & 84.6 & 15.4 \\
\hline 7 & Vaccination and birth registration promotion & 82.5 & 17.5 \\
\hline 8 & Health services used promotion & 50.0 & 50.0 \\
\hline 9 & Family kits distribution promotion & 83.3 & 16.7 \\
\hline 10 & CHWS Overall score practices in accordance with MAP & 80.0 & 20.0 \\
\hline 11 & $\begin{array}{l}\text { CHWS Knowledge of the management of simple } \\
\text { malaria, diarrhea, RID and malnutrition }\end{array}$ & 80.8 & 19.2 \\
\hline 12 & Community Care Sites functionality description & 12.0 & 88.0 \\
\hline
\end{tabular}

\subsection{CHWs Surveyed Profile}

The survey shows that the average age of CHWs surveyed was 46.3 years (AND 9.9). Over half, or $66.7 \%$, were monogamous married; the vast majority of CHWs had been to school, $97 \%$, and almost half, $46.6 \%$, had completed secondary school. In $47.4 \%$ of cases, CHWs practiced the Catholic religion. The majority of CHWs admitted to having a job (97.9\%), in addition to being CHW; and $57 \%$ were farmers.

Most CHWs (80.8\%) have benefited from basic training such as CHW. Several CHWs have also received specific training on different themes, in particular on the management of target diseases. In general, and according to the $\mathrm{HZ}$ continuing education plan, at least one or two CHWs must be trained on behalf of a Community Animation Cell.

In addition, training is also reinforced by the provision of algorithms for the care and treatment of target diseases to CHWs. In addition to the training sessions they organize, the registered nurses and even the members of the HZ management team also provide formative supervision, especially for the CHWs who provide services in community care sites for flagship MAP programs. In total, of the 234 CHWs surveyed, 227 were promotional CHWs, compared to only 7 CHWs providing care as per the limited number of CCS in the survey area. This unbalanced number between the two groups of surveyed may explain the negative judgment of the majority of CHWs on the functioning of CCS. In addition, we should consider the fact that CHWs are receiving better incentives than their colleagues only in charge of promotional activities. It is also important to note that CHWs in charge of CCS were selected among the promotional CHWs and those who were not selected have been frustrated.

This table showed that: 1) Having attended school increases the chances that CHWS contribute to improving health indicators by more than $85 \%(\mathrm{p}=0.000$; $\mathrm{OR}=0.150$ ). This is explained by the fact that, studying increases their comprehension capacities and a better execution of its attributions compared to CMAP; 2) Having sufficient theoretical knowledge on malaria, diarrhea, pneumonia (ARI), malnutrition, availability of inputs to treat these diseases increases the 
chances that CHWS can contribute by $81 \%$ the improvement of indicators in the Mosango RHZ with regard to its attributions $(p=0.004$; OR $=0.192)$. This is explained by the fact that theory governs practice: when CHWS knows its attributions, it can apply them easily; 3) The fact of being trained is a favorable factor which increases to $97 \%$ the chances that CHWS is effective in health activities (P $=0.025 ; \mathrm{OR}=0.024) ; 4)$ And the fact of having undergone more than one training as CHW is a favorable factor which increases by more than $92 \%$ the chances that this CHW is effective with regard to its attributions in health activities ( $\mathrm{p}=$ $0.013 ; \mathrm{OR}=0.074)$.

\subsection{Summary of Health Indicators for Mosango RHZ between 2015 and 2019}

Reading the general trend in the evolution of most of the health indicators of Mosango RHZ shows a clear improvement, since the period of 2015 which marked the intensification of the activities of CHWs, including the establishment of CCS. The increasing figures show that when populations become aware of their state of health, get involved in the implementation of health activities and appropriate interventions in their favor, then they become major players in improving their own health. To do this, the coordinating role of community action played by the CAC is decisive to supervise CHWs.

\subsection{CHWs Assessment on the Perception of the Effectiveness of Their Work in 2019}

Overall, $80.8 \%$ of CHWs received the appropriate basic $\mathrm{CHW}$ training. If $66.7 \%$ have good knowledge on promotional activities, only $20.9 \%$ have sufficient knowledge on the provision of care. This level also justifies the low appreciation (12\%) that CHWs have on the functionality of CCSs. However, it should be noted that the CHW service providers were really in the minority in the study with only 7\%. Nevertheless, indicators for all flagship activities of the PMA-C, including home visits to households, population enumeration and birth registration, promotion of key family practices, promotion of vaccination and recovery those lost to follow-up, as well as the promotion and distribution of family kits, have shown an increasing trend since 2010 or have received a favorable opinion from CHWs.

\subsection{Community Leaders, Health Zone Central Office and CHW Executive's Assessment on the CHWs Work}

The majority of the community leaders interviewed were able to correctly define the function of CHW. They defined him as a person chosen in the community and who bridges his community with the Health Center, but also that CHW is a person who directs patients to the Health Center. Likewise, they argued that the CHWs had sufficient knowledge of their responsibilities. Practically, community leaders have illustrated their assessments in terms of people who oversee the community health and who educate the population on environmental sanitation 
and the fight against diarrhoea with messages such as "Digging garbage holes" or "Practice hand washing and drink potable water". Other messages relate to the fight against malnutrition and confirm that the CHWs exercise their powers by spreading messages like "Madia ya ndonga tatu means the three food groups" translate in the local language. In general, community leaders were able to describe most of the responsibilities of the CHWs that make up the PMA-C, including: sensitizing mothers to bring children to PSC; weigh children during PSC and refer pregnant women to the PNC; hand over the reference tokens to go to the nurse at the HC; count the population; distribute bed net and family kits; and refer tuberculosis and other patients to contact health services. For Health zone central office executives, emphasis has been placed on the oversight of $\mathrm{CHWs}$ by Health zone team members. This contributed to confirming the effectiveness of the implementation of the CHW's powers. For the CHWs themselves, the effectiveness of their work was expressed in terms of implementing active operations in the community, using knowledges received during the training on several themes, in particular the spacing of births and drawbacks of close births; fight against malnutrition; prevention of malaria; combating sexual and marital violence; vaccination; prevention of TB and HIV/AIDS; active participation in grassroots monitoring through $\mathrm{CAC}$ and Health area developing committee meetings.

\subsection{Opinions on the Situation of the Health Zone before and after the Intervention of CHWs}

In the opinion of the majority of Focus Group participants, the situation of the $\mathrm{HZ}$ before the involvement of CHWs was characterized by: numerous deaths at home, traditional self-medication, numerous home births, frequent cases of malnutrition (Kwashiorkor) also called "Muwangi" or "Kimbengi" in the local language. In addition, pregnant women did not want to attend ANC, splenomegaly called "Kibekele" was very common, the population refused vaccination and rarely attended health facilities, and "habits and customs" adversely affected the health of the mother and the child. Since the intervention of the CHWs, the participants recognized that progress is observable in the communities and that the recordings made at the level of the Health Centers should confirm these improvements. However, in the field, participants noted that "Attendance at health centers has increased and more home deliveries are registered"; "The message passes easily between the community and the health centers thanks to the CHWs", and that "The CHWs intervene during the PSC for taking anthropometric measurements and screening for malnutrition". Despite all the advances mentioned, the participants also made proposals to improve the involvement of CHWs in the activities of the HZ. Among the measures proposed, mention should be made of 1 ) the need to intensify the organization of basic and thematic training for CHWs, 2) the consolidation of monitoring and supervision activities for CHWs, 3) evaluation of the actual performance of the CHWs. In addition, the participants asked for the CHWs to be given distinctive signs to enhance 
their value in the eyes of the communities. In this regard, the following requests can be reported: "I think that the CHWs should be provided with work clothes, distinctive badges in order to identify them in the community, documents proving that they are CHWs and free of charge medical care at the level of the HC and GH for the CHW and its family 'or' to motivate the CHWs of the Mosango RHZ: Organize testimonial sessions of active CHWs to motivate the non-active; certification or delivery of patents to CHWs; delivery of distinctive signs to CHWs: hats, T-shirts, membership cards, small CHW bags, bikes, megaphones, to enhance their value; organize trips for exchange of $\mathrm{CHW}$ experience; organize CHW contests". In addition, voices were also raised asking the Ministry of Health to think about the remuneration of the CHWs in relation to the task they are carrying out.

\section{Discussion}

The principal aim of this study was two-fold. The first aim was to identify in which context, with what mechanisms can the introduction of CMAP under the responsibility of CHWS is a major intervention which contributes to the improvement of health service indicators. The second aim was to make relationship between the improvement of health service indicators and the effectiveness of this community intervention was conditioned by capacity building of the CHWs, the availability of inputs and the involvement of the community in the activities of the health zone through the Community Animation Cells (CAC). To this end, we used a conceptual framework model adapted from Pawson and Tilley [8] [18], which allowed us to identify all mechanisms and inputs in Mosango RHZ who conduct to produce all effects like the improvement of health service indicators. This study has highlighted some enabling and constraining factors as being important to improve health service indicators.

The majority of CHWs $97 \%$ had studied, of which almost half $46.6 \%$ had completed secondary school. Our results corroborate those of the DHS II which indicate in relation to the level of study, that in the DRC, the majority of the population has studied and is at the secondary level: $47 \%$, and those of a survey conducted by Kadiri Mohammed and Wafae at 2017 in Morocco with 51\%. [2] [19] [20] [21] [22].

$35.9 \%$ of CHWs received training on the distribution and promotion of bed nets, $29.5 \%$ on treatment and prevention of simple malaria: on February 2014, this result is lower than that found and published by USAID in its final report on the evaluation of community management of malaria in the pilot health districts of Gahombo, Gashoho and Mabayi in Burundi, which showed that $67 \%$ of CHWs had declared having undergone training on the management of case of children simple malaria. At 2017 in Morocco the study insists that this training aims at $62 \%$ help to provide CHW with the skills necessary to carry out certain strategies of universal health coverage through the census of beneficiaries as well as the communication of proximity for behavior change [23] [24] [25]. 
In addition to being CHWs, $97 \%$ of CHWs had another occupation, $57 \%$ were farmers. This result is close to the previous study carried out in Benin by Cossi Angelo who found $60.3 \%$ of CHWs growers [26]. These results also corroborate with those of the DHS II which show that in our country as a whole (DRC), agricultural activities constitute $70 \%$ of the occupations of the population in rural areas [2].

99.6\% of CHWs carried out home visits, $80.3 \%$ had control over population counts (children under 5, pregnant women, deaths), $84.6 \%$ advised families on promotion of key family practices, $82.5 \%$ on vaccination and birth registration, $83.3 \%$ contributed to the distribution and promotion of family kits: These results are slightly lower to that of a previous study carried out in Benin at 2012 by Panaveyi Vicky et al., which evaluated the effectiveness of CHWs at $97.4 \%$ and in Mali in 2015 by Saint Firmin and all showed that population counting activities, family kits distribution, the orientation of children for vaccination, the availability of inputs coupled with home visits reinforce community participation in rural areas at 96.8\% [27] [28] [29] [30] [31].

As such, in many countries, community health workers are among the interdisciplinary workforce. They have particular roles in primary health care and essential public health functions. The Global Strategy recognizes that community health workers and other categories of health workers working at this level are effective in providing a range of preventive, curative and promotional services, and can help to reduce inequalities in access to care [32].

\section{Conclusion}

The involvement of CHWs on improving demand for health services is effective in Mosango RHZ insofar as CHWs are operational on a voluntary basis. They are implementing CMAP while encouraging the community through the Community care sites to become more involved in increasing the demand for health services. Their activities are thus supported by the CACs and supervised mainly by Nurses from the Health Centers in their responsible health areas as well as by members of the Mosango RHZ Management Team. The improvement of health service indicators and the effectiveness of this community intervention were conditioned by capacity building of the CHWs, the availability of inputs and the involvement of the community in the activities of the health zone through the Community Action Cells. It is under these conditions that we observe a certain evolution in the health indicators reported by the HZ. Thus, despite the questioning of administrative data quality, we noted an increase in health coverage rates for several indicators, between 2015 and 2019.

\section{Ethics Approval and Consent to Participate}

Written informed consent was obtained from all study participants. The University of Kinshasa Ethic Committee approved all protocols (Reference number: $\mathrm{ESP} / \mathrm{VD} / \mathrm{DIR} / \mathrm{CE} / 223 / \mathrm{KL} / 2018$ ). 


\section{Conflicts of Interest}

The authors declare no conflicts of interest regarding the publication of this paper.

\section{References}

[1] Ministère de la Santé Publique. Plan national de développement sanitaire 2016-2020: Vers la couverture sanitaire universelle.

http://www.nationalplanningcycles.org/sites/default/files/planning cycle repository /democratic republic of congo/pnds 2016-2020 version finale 29 avril 2016.pdf

[2] Ministère du Plan et Suivi de la Mise en CEuvre de la Révolution de la Modernité MdlSPMeII. Enquête Démographique et de Santé en République Démocratique du Congo 2013-2014. Rockville, Maryland, États-Unis d'Amérique: MPSMRM, MSP et ICF International.

[3] Organisation mondiale de la Santé. Improving Health System Efficiency in DRC. http://apps.who.int/iris/bitstream/10665/186673/1/WHO HIS HGF CaseStudy 15 .4 eng.pdf

[4] Black, R.E., et al. (2017) Comprehensive Review of the Evidence Regarding the Effectiveness of Community-Based Primary Health Care in Improving Maternal, Neonatal and Child Health: 8. Summary and Recommendations of the Expert Panel. Journal of Global Health, 7, Article IDC: 010908.

https://doi.org/10.7189/jogh.07.010908

[5] http://www.reliefweb.org

[6] Ministère de la Santé Publique/République Démocratique du Congo (2016) Manuel des procédures du relais communautaire, cellule d'animation communautaire et comité de développement de l'aire de santé. MSP, Kinshasa.

[7] WHO (2018) WHO Guideline on Health Policy and System Support to Optimize Community-Based Health Worker Programmes.

https://www.who.int/hrh/community/en

[8] Etshumba, J.M., Bebe, D.N., Kalambay, P.K. and Nappa, F.K. (2020) How to Develop a Realist Evaluation to Evaluate the Effectiveness of Integrated Management Child Hood Illness Strategy in Community Care Sites in the Democratic Republic of Congo. Open Journal of Epidemiology, 9, 243-258. https://doi.org/10.4236/ojepi.2019.93019

[9] Maluka, S.O. and Bukagile, G. (2016) Community Participation in the Decentralised District Health Systems in Tanzania: Why Do Some Health Committees Perform Better than Others? International Journal of Health Planning and Management, 31, E86-E104. https://doi.org/10.1002/hpm.2299

[10] Amouzou, A., et al. (2016) Effects of the Integrated Community Case Management of Childhood Illness Strategy on Child Mortality in Ethiopia: A Cluster Randomized Trial. American Journal of Tropical Medicine \& Hygiene, 94, 596-604. https://doi.org/10.4269/ajtmh.15-0586

[11] WHO, UNICEF (2018) Déclaration d'Astana. Genève. https://www.who.int/docs/default-source/primary-health/declaration/gcphc-declara tion-fr.pdf

[12] WHO, UNICEF (2018) A Vision for Primary Health Care in the 21st Century: Towards Universal Health Coverage and the Sustainable Development Goals. Genève. https://www.who.int/docs/default-source/primary-health/vision.pdf 
[13] World Health Statistics (2018) Monitoring Health for the SDGs, Sustainable Development Goals. World Health Organization, Genève.

[14] WHO, UNICEF, World Bank Group (2018) Nurturing Care for Early Childhood Development: A Framework for Helping Children Survive and Thrive to Transform Health and Human Potential. World Health Organization, Genève.

[15] Arifeen, S., Christan, A., Rechenback, L., et al. (2013) Community Based Approaches and Partnerships: Innovations in Health Service Delivery in Bangladesh. The Lancet, 382, 2012-2026. https://doi.org/10.1016/S0140-6736(13)62149-2

[16] De Vries, D.H. and Pool, R. (2017) The Influence of Community Health Resources on Effectiveness and Sustainability of Community and Lay Health Worker Programmes in Lower-Income Countries: A Systematic Review. PLoS ONE, 12, e0170217. https://doi.org/10.1371/journal.pone.0170217

[17] Kinshasa School of Public Health, University of Kinshasa (KSPH) et ICF (2019) Evaluation des Prestations des Services de soins de Santé (EPSS RDC) 2017-2018. Kinshasa, RDC, KSPH et ICF International, Rockville. http://www.DHSprogram.com

[18] Pawson, R. and Tilley, N. (1997) Realistic Evaluation. Sage Publications Ltd., London.

[19] Kadiri, M. and Wafae, C. (2017) Evaluation de l'implantation des approches basées sur les personnes Relais Communautaires dans la mobilisation sociale en santé rurale: Cas de la Région Marrakech-Safi, ENSP, Maroc, 25 p.

[20] Kok, M.C., Dielman, M., Taegtmeyer, M., Broerse, J.E., Kane, S.S., Ormel, H., et al. (2014) Which Intervention Design Factors Influence Performance of Community Health Workers in Low- and Middle-Income Countries? A Systematic Review. Health Policy Plan, 30, 1207-1227. https://doi.org/10.1093/heapol/czu126

[21] Roberton, T., Applegate, J., Lefevre, A.E., Mosha, I., Cooper, C.M., Silverman, M., et al. (2015) Initial Experiences and Innovations in Supervising Community Health Workers for Maternal, Newborn and Child Health in Morogoro Region, Tanzania. Human Resources for Health, 13, 19. https://doi.org/10.1186/s12960-015-0010-x

[22] Kangovi, S. and Asch, D.A. (2018) The Community Health Worker Boom.

[23] USAID (2014) Rapport Final: Evaluation de la prise en charge communautaire des maladies de l'enfance dans les districts sanitaires pilotes de Gahombo, Burundi.

[24] UNICEF (2015) A Decade of Tracking Progress for Maternal, Newborn and Child Survival. The 2015 Report. http://countdown2030.org/2015/2015-final-report

[25] Cometto, G., et al. (2018) Health Policy and System Support to Optimise Community Health Worker Programmes: An Abridged WHO Guideline. The Lancet Global Health, 6, e1397-e1404. https://doi.org/10.1016/S2214-109X(18)30482-0

[26] Cossi, A., et al. (2017) Connaissances et attitudes des relais communautaires sur les fièvres hémorragiques à virus Lassa et Ebola dans le département de la Donga (Nord Bénin). Pan African Médical Journal, 1-3.

[27] Panaveyi, V., et al. (2014) Qualité de l'apport des relais dans la PCIME communautaire au bénin. Afrique Santé publique et Développement, Ouidah-Bénin, 241-248. https://doi.org/10.3917/spub.138.0241

[28] Saint Firmin, P., Diakité, B.D. and Diawara, A. (2017) Analyse situationnelle de la prestation des soins essentiels via les agents de sante communautaires au Mali en 2015: Résultats et conclusions clés. Palladium, Health Policy plus, Washington DC.

[29] Meghani, A., Abdulwahab, A., Privor-Dumm, L. and Wonodi, C. (2015) Basket Funds: A Pooled Arrangement to Finance Primary Health Care Delivery and Ad- 
dress the Funding Flow in Nigeria. International Vaccine Access Center (IVAC). http://www.jhsph.edu/ivac

[30] Sakha, A.M., Rashidian, A., Bazyar, M., Sari, A.A., Yazdani, S. and Moghadam, A.V. (2017) Health Financing Assessment and Policy Analysis toward Universal Health Coverage: A Systematic Review of Qualitative Research. Global Journal of Health Science, 9, 131.

[31] Crigler, L., et al. (2013) Community Health Worker Assessment and Improvement Matrix (CHW AIM): A Toolkit for Improving CHW Programs and Services-Revised Version. USAID Healthcare Improvement Project.

http://www.who.int/workforcealliance/knowledge/toolkit/CHWAIMToolkit Revisi on Sept13.pdf

[32] WHO (2018) A Healthier Humanity: The WHO Investment Case for 2019-2023. World Health Organization, Genève.

http://apps.who.int/iris/bitstream/handle/10665/274710/WHO-DGO-CRM-18.2-en g.pdf

\section{List of Abbreviations}

ARI: Acute Respiratory Infection

CAC: Community Animation Cell

CCS: Community Care Site

CHW: Community Health Worker

CSBC: Communication for Social and Behavioral Change

DRC: Democratic Republic of Congo

DHIS2: Data Health Information System Software 2

DHS: Demographic and Health Survey

FGD: Focus Group Discussion

FP: Family Planning

GH: General Hospital

HADC: Health Area Development Committee

HC: Health Center

HRZ: Health Rural Zone

HZCO: Health Zone Commitee Office

HZMT: Health zone management team

IMAM: Integrated Management Acute Malnutrition

IMCI: Integrated Management Child Hood Illness

MCAP: Minimum Community Activities Package

MICS: Multi Indicators Cluster Survey

PHC: Primary Health Care

PNC: Pre Natal-Consultation

PSC: Pre School Consultation

RHC: Reference Health Center

WHO: World Health Organization 